\title{
Environmental management in the field of noise impact on recreational, public and agricultural areas
}

\author{
Mariya Balmashnova ${ }^{1, *}$ and Tatyana Sorokoumova ${ }^{1}$ \\ ${ }^{1}$ Moscow State University of Civil Engineering, 26, Yaroslavskoye Shosse, 129337, Moscow, Russia
}

\begin{abstract}
As a result of increase in the number of residents of megacities, the anthropogenic impact on the public, recreational and agricultural areas is increasing. Anthropogenic load causes degradation of the natural structure of the city and has a negative impact on public health. In current situation, more recreational areas are organized for residents of the city. However, the organization of recreational areas does not always comply with the population requirements. In the formation that sort of spaces, it is necessary to obtain complete and reliable information about the quality of the environment, which can only be obtained through the regular monitoring studies. This article considers a number of recreational, agricultural and public areas under the noise exposure. The spatial organization of recreational areas should be carried out taking into account the main goal of creating a comfortable architectural and planning structure of the urban environment. This article shows the insolvency of the public, recreational and agricultural areas as comfortable spaces.
\end{abstract}

\section{Introduction}

Nowadays, current urban environment, one of the factors that which has a detrimental effect to the mental and physiological state of a person is a noise pollution. Sources of noise in cities are human, all types of transport, ventilation systems of residential and public buildings, industry. Besides, the noise pollution of urban areas is increasing in conditions of suboptimal urban planning, insufficient green areas and the lack of soundproofing measures. In terms of human perception of sounds, any unfavorably perceived sound is considered as noise. This perception is due to the frequency and difference in intensity and frequency of this type of sound. Noise figures of 70-90 dB are perceived by the hearing organs as an extremely unfavorable irritant; sound pressure levels above $100 \mathrm{~dB}$ has a negative development on the human body and can lead to serious illness [1-7].

As a result of research [8], a correlation was found between changes in the psychophysiological parameters of the nervous system, as well as the presence of chronic diseases and the constant effect of acoustic noise on the human body. According to the World Health Organization (WHO), cardiovascular disease occurs much more often when a

\footnotetext{
* Corresponding author: Balmashnova97@mail.ru
} 
noise level of $50 \mathrm{~dB}$ or higher affects the auditory system. This indicator of sound level is characterized by a street with heavy traffic and is quite common in modern cities.

A lower noise level (35-42 dB) contributes to the development of insomnia and a general deterioration in the mental and physical condition of a person [9-11]. It is proved that the load on the hearing aid negatively affects the human nervous system, which, in turn, affects both the general condition of the person and his performance.

\section{Materials and Methods}

To analyze the average noise pollution of existing recreational territories, 3 public spaces were selected on the territory of Moscow: Triumfalnaya Square, the square in front of the Library named after Lenin, Khokhlovskaya Square (fragment of the walls of the White City). Using specialized equipment, the sound pressure level was measured on the analyzed public areas to assess for their safety and comfort.

Triumphal Square. This object was chosen as a public-use territory for annual use. The area is located in the central administrative district of Moscow and is limited to Tverskaya Street (main street of urban importance, speed - up to $80 \mathrm{~km} / \mathrm{h}$ [Error! Reference source not

found.]) and 1st Brest street (speed - not more than $60 \mathrm{~km} / \mathrm{h}$ [Error! Reference source not found.]). This territory perceives a large load from transit pedestrian flows.

Measurements of the noise level by the instrumental method at different sites of the selected research object showed from $66 \mathrm{~dB}$ to $96 \mathrm{~dB}$, which exceeds the recommended noise levels for this type of urban area and creates unfavorable conditions on the territory of the Triumphal Square even for a short-term residence. Despite of the green spaces existence which are provided for by the area improvement project, the existing noise protection measures are not enough to protect the recreation area from the effects of traffic noise.
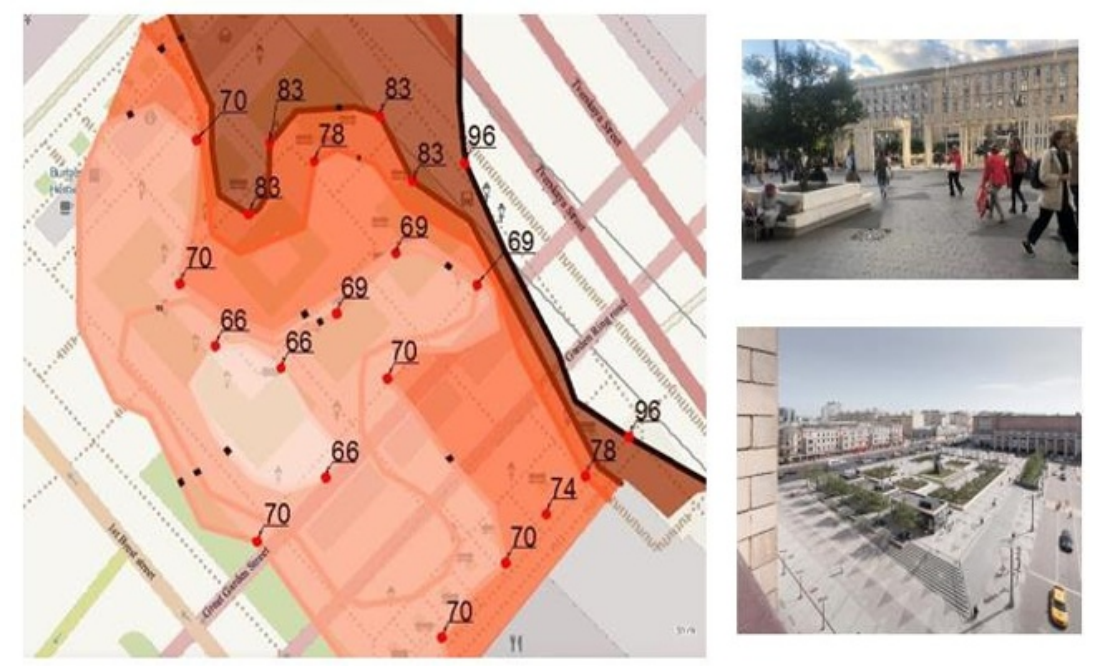

Fig. 1. Analysis of noise activity at the Triumfalnaya facility.

The existance of open space nearby of the large transport corridor (Tverskaya Street), the main source of noise, contributes to the unhindered distribution of sound throughout the area, which reduces the effectiveness of the use of noise protection in the territory, and also makes a significant part of the territory unsuitable for using by people in the recreational purposes. 
The square in front of the Lenin Library is organized at the intersection of Vozdvizhenka Street and Makhovaya Street. This territory is social and recreational in the certain months, its use is dedicated to various city festivals. The recorded average of noise level in the territory does not exceed $72 \mathrm{~dB}$, however beside of the streets it is $76 \mathrm{~dB}$.

The sound pressure level of $72 \mathrm{~dB}$ is a critical point acceptable in the formation of public spaces. Greenery, in the territory (Fig. 2) which can reduce the degree of noise pollution are temporary, that is why it could solve the problem of the comfort of staying in the analyzed territory only for a short period of time.

With the lack of greenery in the territory, the noise impact from vehicles makes the public space in front of the Library unsuitable for use for recreational purposes throughout the year. Most of the year, this territory is transit, despite of the great recreational potential associated with the location, the absence of problems with transport and pedestrian access, and also the presence of "objects of attraction" of the population in this area of the city.
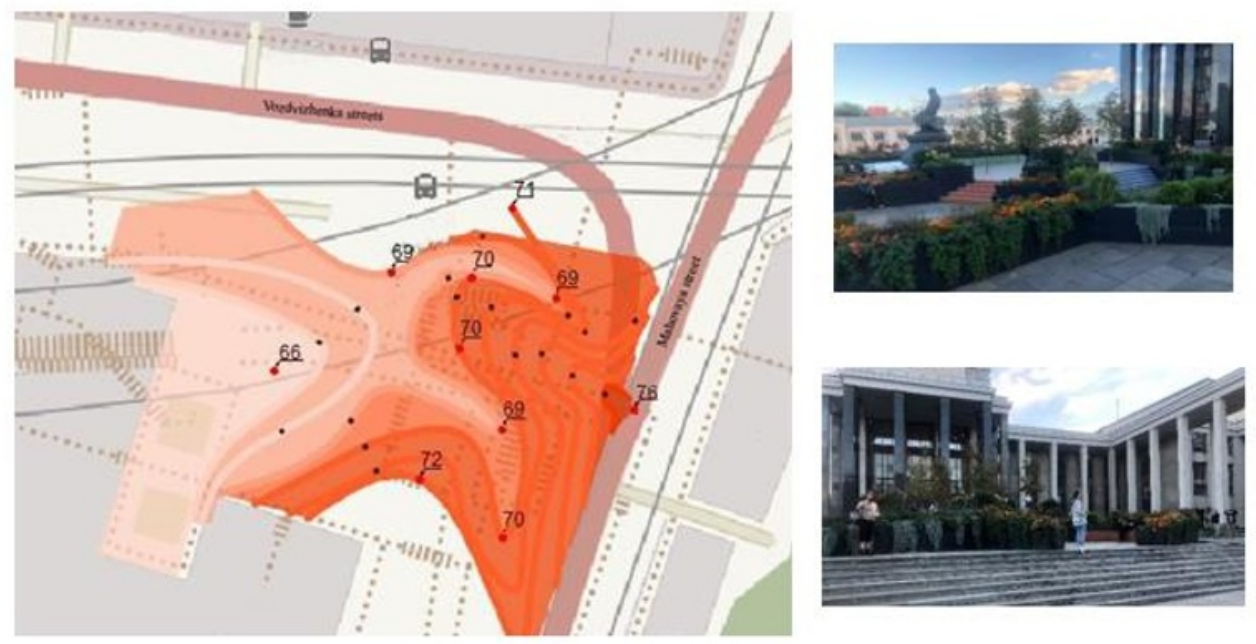

Fig. 2. Analysis of noise activity at the facility in front of the Lenin Library building.

Khokhlovskaya Square is bounded on both sides by busy roads and tram tracks, which may indicate the typical problem of traffic noise in the formation of public spaces in megacities. Measurements of noise pollution showed average values of the sound pressure level of 60-70 dB. These rates are not available for extended stays. 

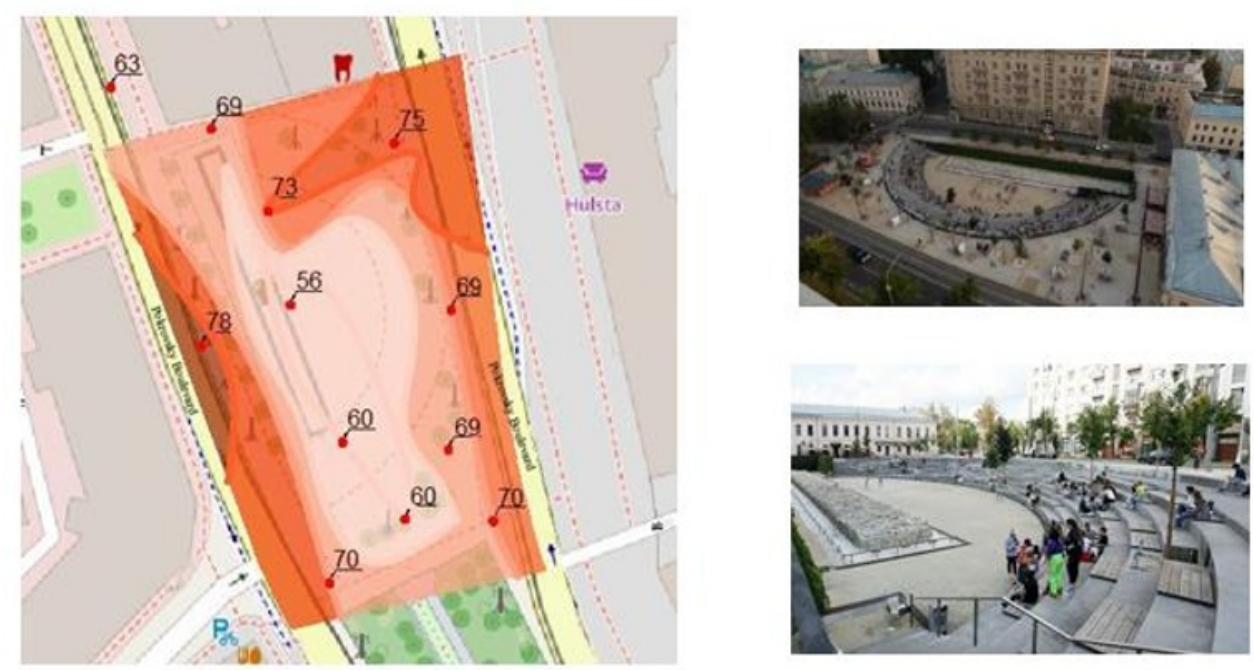

Fig. 3. Analysis of noise activity at the Khokhlovskaya.

In addition to protection from the effects of traffic noise on the territory, the need in the protective measures are appeared. This measures are aimed both at the public space and the surrounding territories against of the noise exposure from visitors of the square. The planning organization of this territory only contributes to the spread of sound waves, that have a negative impact both on residents of nearby houses and on visitors to public space.

Despite of the fact that the noise of vehicles has become usual for the residents of the city, and Khokhlovskaya Square, regardless of the level of noise pollution, has high attendance rates, the creation of a protected space from noise exposure contributes to a more comfortable stay of the population in these areas.

\section{Conclusion}

As a result of the analysis and assessment of the noise impact on the public areas of Moscow, the similarity of problems inherent in urban recreational spaces was revealed:

- the main source of noise is cars;

- a large number of public spaces adjacent to the transport corridors;

- noise is promoted by the open architectural and planning organization of territories;

- there is a lack of existing soundproofing measures to create a safe urban environment;

- lack of activities to reduce sound levels.

The historical and physical formation of public spaces determines their spatial organization. Squares, as one of the most common types of public spaces, are often limited by highways. A large number of recreational spaces are arranged along the rivers. The different territories, various soundproofing measures are required. Soundproof screens are not only making worse the aesthetic parameters of the environment, but can also make the area less safe and comfortable to visit.

Adherence to public spaces of high-speed transport corridors directly affects noise pollution on it. Acording to the urban planning documentation «GOST R 52289-2004 "Technical means of traffic management. Rules for the use of road signs, markings, traffic lights, road fences and guiding devices " vehicle speed affects the intensity and frequency of negative noise impacts on the territory. Noise reduction is also possible with a rational organization of road traffic in territories adjacent to public spaces. 
For example, the absence of regulated pedestrian crossings on two-lane highways can reduce the sound pressure level that occurs both the traffic light is on the vehicle stops and when it's beginning their movement again. A decrease in the average speed of movement along highways which is limiting the public spaces also contributes to an increase in the comfort and safety of the urban environment.

The need of a modern person in public spaces where a long stay is possible without adverse effects on health and general physical condition dictates the need to change the approach to the formation and reorganization of these spaces.

The design and reconstruction of recreational areas (in particular, urban areas and squares, which are more susceptible to noise from automobile transport) should be based on an integrated approach, ensuring the formation of an enabling environment for recreation and recreation. A significant impact of noise on the comfort of staying in public space necessitates the installation of additional noise protection measures, and in some cases, a complete reorganization of the architectural and planning decisions of the territory.

In the context of the modern city and its inhabitants, public spaces play a crucial role not only for the recreation of the population, but also within the framework of the social, political and economic spheres of society. Modern man spends more and more time in the established centers of society, this, in turn, speaks of the relevance and significance for designers of a change in the approach to the arrangement of public spaces. First of all, given the level of motorization of large megacities of the world, it is necessary to pay attention to noise pollution during the design and reconstruction of public areas.

The organization of space should meet safety requirements and minimize noise impact on the human body visiting public spaces, and on the population living in adjacent territories. an integrated approach to the analysis, planning and design of a public zone is important.

\section{References}

1. Russian Federation Standard GOST 20444-2014

2. Russian Federation Standard GOST 23337-2014

3. Russian Federation Standard GOST 23941-2002

4. Russian Federation Standard GOST R ISO 3746-2013

5. Report "On the state of working conditions and occupational morbidity in the Russian Federation"

6. A.Yu. Popova, Report of the head of the Federal Service for Supervision of Consumer Rights Protection and Human Well-being (2014)

7. A. Popova, On the state of working conditions and occupational morbidity (2014)

8. N.I. Ivanov, Engineering acoustics. Theory and practice of noise control (Logos, Moscow, 2013) http://www.iprbookshop.ru/9080.html

9. V.I. Karpova, Noise reduction in urban environments (2015)

10. I.A. Pogonysheva, D.A. Pogonyshev, A.A. Krylova, Bulletin of the NVUH 1 (2015) https://cyberleninka.ru/article/n/vliyanie-shuma-na-psihofiziologicheskie-parametry-irabotosposobnost-organizma-cheloveka.

11. Decree of the Government of the Russian Federation of 10.23 .1993 N 1090 (as amended on 04.12.2018) "On the Rules of the Road"

12. T.T. Shishelova, Yu.S. Malygina, N.S. Dat, Successes in modern natural sciences 8 , 14-15 (2009) 
13. A. Bell, Noise: occupational harm and public evil (World Health Organization) https://apps.who.int/iris/handle/10665/86351 